\title{
NATURAL OCCURRENCE OF ALTERNARIA TOXINS IN POMEGRANATE FRUIT AND THE INFLUENCE OF SOME TECHNOLOGICAL PROCESSING ON THEIR LEVELS IN JUICE
}

\author{
H.M. Elhariry ${ }^{\mathrm{a}, b *}$, G.M. Khiralla ${ }^{\mathrm{c}}$, Y. GherbawY ${ }^{\mathrm{a}, \mathrm{d}}$ and H. AbD ElRahman ${ }^{\mathrm{b}}$ \\ ${ }^{a}$ Department of Biology, Faculty of Science, Taif University, PO Box: 888-Taif. Kingdom of Saudi Arabia \\ ${ }^{b}$ Department of Food Science, Faculty of Agriculture, Ain Shams University, PO Box 68-Hadayek Shoubra, \\ Cairo 11241. Egypt \\ ${ }^{\mathrm{c}}$ National Organization for Drug Control and Research (NODCAR), 6-7, Abo Hazem Street, Pyramids, PO Box \\ 29, Giza. Egypt \\ ${ }^{\mathrm{d} D e p a r t m e n t}$ of Botany, Faculty of Science, South Valley University, 83523 Qena Egypt
}

(Received: 21 September 2015; accepted: 3 November 2015)

\begin{abstract}
Alternaria species produce several mycotoxins that are of particular health concern. The natural occurrence of three Alternaria toxins; alternariol (AOH), alternariol methyl ether (AME), and tenuazonic acid (TA) in pomegranate fruit was considered. A. alternata and A. tenuissima were identified by analysis of partial sequence of ITS-region. All studied strains produced high quantities of $\mathrm{AOH}$ in vitro on rice. A. tenuissima produces high quantities of AME and TA compared with A. alternata. In rotten tissues AME was the highest determined toxin with frequency percentage of $95.6 \%$, followed by AOH and TA. All toxins were detected in the healthy tissues surrounding the infected tissues but at low levels. No visible changes were noted in Alternaria toxins after pasteurization of pomegranate juice, but they appeared after clarification. In conclusion, pasteurization and/or clarification are not sufficient to reduce Alternaria toxins in juice. The removal of the rotten parts does not ensure excluding Alternaria toxins.
\end{abstract}

Keywords: pomegranate, Alternaria, alternariol, alternariol methyl ether, tenuazonic acid, juice

Pomegranate (Punica granatum, Punicaceae) has high nutritional and medical value mainly due to its exceptional and unique sensory and nutritional properties (VIUDA-MARTOS et al., 2010). The most destructive disease observed on pomegranate trees causes a leaf blotch and fruit spot (EzRA et al., 2010). Fruit symptoms are small, conspicuous, dark brown spots, initially circular and becoming irregular. Alternaria alternata has been reported as a postharvest disease causal agent of pomegranate in Greece (PANTIDOU, 1973). Black rot of the fruit core is starting from the calyx region, while the hard leathery rind appeares healthy and fruit remains firm. Although this disease has been detected previously in Greece (PANTIDOU, 1973), it was noticed again only recently, probably due to the recent expansion of pomegranate cultivation and changes in weather conditions. Therefore, another report of A. alternata causing fruit decay in pomegranate orchards in Greece has been published in 2008 (TzIRos et al., 2008). Moreover, fruit rot caused by Alternaria sp. has previously been reported in the USA and in Mexico (FARR et al., 2007). In 2009, study on integrated management of Alternaria alternata causing rot of pomegranate fruit has been conducted (DAHIWALE et al., 2009). In 2010, the first report on black spot disease of pomegranate caused by A. alternata on pomegranates in Israel has been published as a new disease. Symptoms have been seen on

* To whom correspondence should be addressed.
Phone: +201226458647; fax: +202444 4460; e-mail: h.elhariry@agr.asu.edu.eg

0139-3006/\$20.00 @ 2016 Akadémiai Kiadó, Budapest 
the leaves and fruit, but no damage to the inner edible tissue has been found (EzRA et al., 2010).

Alternaria toxins have been found in fruit, such as apples, blueberries, cherries, and several citrus fruit. Alternaria species produce more than 70 phytotoxins. Some toxins, such as $\mathrm{AOH}$ and $\mathrm{AME}$, are non-host-specific toxins and are concern for public health. These toxins are described to induce harmful effects in animals, including teratogenic, mutagenic, and clastogenic effects in various in vitro systems (BARKAI-GOLAN, 2008). TA is toxic to chicken embryos and can cause haemorrhage and death in mice (DA MotTA \& SoARes, 2000b). AOH, AME, and TA have been found in different fruit, such as olives, mandarins, apple, and peaches (RoBiglio \& LóPez, 1995; Pose et al., 2010).

To the best of our knowledge, there are little information on the pomegranate fruit infection with fungi, and no available information about the presence of mycotoxins in pomegranate fruit or their fresh and processed juices. The pasteurization is the most commonly used preservation technique to extend the shelf-life of juices. However, this process may have adverse effects on sensory and nutritional properties of juices, particularly colour quality of anthocyanin containing juices, which is undesirably lost during thermal process (PATRAs et al., 2010). Therefore, the consumer demands for freshly squeezed fruit juices, but such products are susceptible to spoilage and thus have a limited shelf-life (BuZRUL et al., 2008). In the case of the preparation of juice from fruit contaminated with toxin-producing fungi, there is a high probability for the transfer of these toxins to the consumers.

The aim of the current study was to: i) determine the species of Alternaria causing black spots resulting in mouldy heart of pomegranate fruit collected from local market of Taif City, KSA, ii) identify their ability to produce $\mathrm{AOH}, \mathrm{AME}$, and TA in rotten fruit, and iii) evaluate the effect of pasteurization and/or clarification during juice preparation on the presence of these mycotoxins.

\section{Materials and methods}

\subsection{Sample collection and cultural technique}

Healthy-appearing and black-spotted pomegranate fruit were collected from the local market of Taif City, KSA. Pieces of the healthy and rotten tissues from the inner surface were placed onto malt agar (MA) with penicillin $\mathrm{G}$ and chloramphenicol (MApc, $75 \mathrm{mg} \mathrm{l}^{-1} \mathrm{MA}$ ) and incubated at $30{ }^{\circ} \mathrm{C}$ for 5 days. Pure cultures were obtained by transferring hyphal tips to MApc. Isolates were maintained on MApc at $4{ }^{\circ} \mathrm{C}$, and identified by macroscopic and microscopic observations. Identification of isolated fungi was carried out based on the book of Pitt and Hocking (1997).

\subsection{Molecular identification}

Fungal strains were cultured in $100 \mathrm{ml}$ Erlenmeyer flasks containing $20 \mathrm{ml}$ potato dextrose broth (PDB) for 5 days using a rotary shaker $\left(30^{\circ} \mathrm{C}, 150\right.$ r.p.m.). The mycelium was collected by filtration and ground to fine powder in liquid nitrogen. The genomic DNA of fungal isolates was extracted using the Fungi/Yeast Genomic DNA Isolation Kit (Norgen, Biotek Corp., Canada). From the nuclear rDNA, the ITS regions (ITS1 and ITS2) and the 5,8S rRNA gene were amplified by PCR using the primer set ITS1 ( $5^{\prime}$ tccgtaggtgaacetgcgg $\left.3^{\prime}\right)$ and ITS4 (5' tcctccgettattgatatgc $3^{\prime}$ ) (WhITE et al., 1990). PCR protocol described by GARDES and BRUND, (1993) was applied. The PCR product was excised from the ethidium bromide-stained 
gel and purified using a purification kit (QIAquick Gel Extraction Kit, Qiagen) according to the manufacturer's protocol. All of sequenced strains were identified by similarity searches with ITS sequences at the website of NCBI database. The nucleotide sequence data obtained in the current work were submitted to the EMBL Nucleotide Sequence Database (Table 1).

Table 1. Identification of Alternaria strains by alignment with the sequences of fungi in the NCBI database

\begin{tabular}{lccc}
\hline Proposed identity & Accession No. & $\begin{array}{c}\text { Identity according to } \\
\text { CBS (\%) }\end{array}$ & $\begin{array}{c}\text { Database accession } \\
\text { No. }\end{array}$ \\
\hline Alternaria tenuissima TUAa1 & HG974556 & 100 & KT598351.1 \\
Alternaria tenuissima TUAa2 & HG974557 & 100 & JX406579.1 \\
Alternaria tenuissima TUAa3 & HG974558 & 100 & KC415611.1 \\
Alternaria alternata TUAa4 & HG974559 & 100 & KF638335.1 \\
Alternaria alternata TUAa5 & HG974560 & 100 & JF835808.1 \\
Alternaria alternata TUAa6 & HG974561 & 100 & KF907249.1 \\
Alternaria tenuissima TUAa7 & HG974562 & 100 &
\end{tabular}

\subsection{Preparation of pomegranate juice}

Two sets of pomegranate juices were prepared in the present study (Fig. 1). The first was prepared from healthy-appearing fruit and the second set was prepared from the rotten fruit after removing the infected tissues. Raw pomegranate juice (RPJ) was extracted as described by RINALDI and co-workers (2013). Pomegranate fruit were washed with tap water and manually separated into arils. The RPJ was extracted from arils by electric fruit crusher. The extracted juice, having a deep-red colour, was prefiltered with a stainless steel filter. Then it was stored in a refrigerator at $-20^{\circ} \mathrm{C}$ and defrosted before use. Clarified pomegranate juice (CPJ) was obtained by treating the RPJ with $15 \mu 1 \mathrm{l}^{-1}$ pectolytic enzymes solution (Erbslöh Geisenheim, Germany) for $120 \mathrm{~min}$ at $25{ }^{\circ} \mathrm{C}$ (RINALDI et al., 2013). Pasteurization of pomegranate juice was achieved in glass bottles $(200 \mathrm{ml})$ at $95{ }^{\circ} \mathrm{C}$ for $7 \mathrm{~min}$ by immersion in a hot water bath. The juices were then cooled under tap water (ElHariRY et al., 2011). Pasteurized pomegranate juices were named as PRPJ for pasteurized raw pomegranate juice and PCPJ for pasteurized clarified pomegranate juice. H and I letters were added to the abbreviations of juices prepared from healthy-appearing and rotted fruit, respectively.

\subsection{In vitro production of Alternaria toxins}

The ability of fungal isolates to produce mycotoxins was in vitro determined (Pose et al., 2010).

\subsection{Alternaria toxins in the pomegranate tissues and juices}

Alternaria toxins; AHO, AME, and TA were determined in rotted and surrounding healthy tissues. Also, these toxins were assayed in pomegranate juices prepared from healthy appearing fruit and from rotted fruit after removing infected tissues. Extraction and determination of mycotoxins were achieved as described by DA MotTA and SoAres (2000a). 


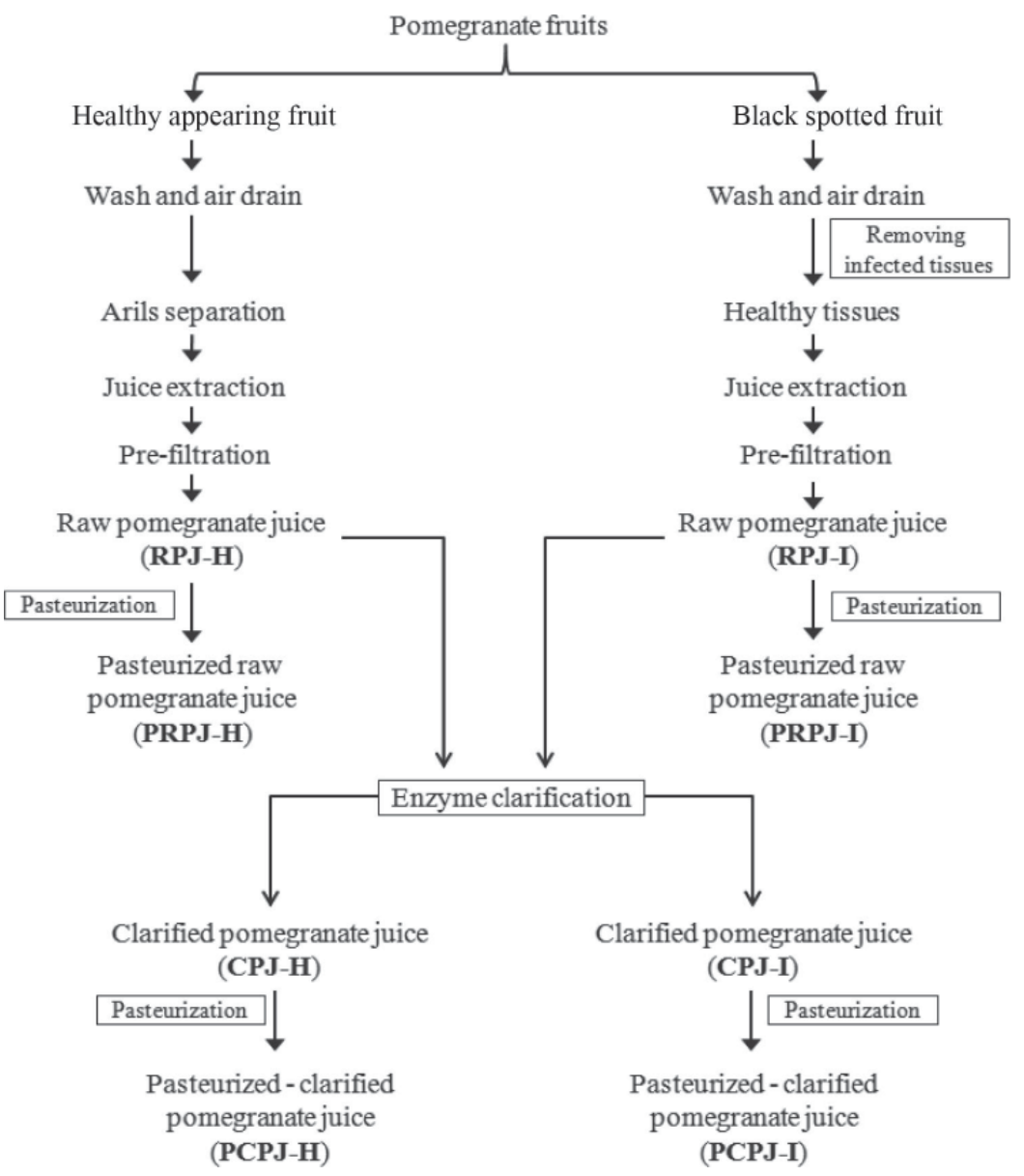

Fig. 1. Production scheme of pomegranate juices

\subsection{Statistical analysis}

All data were statistically evaluated by ANOVA test $(\mathrm{P}=0.05)$, performed with the Statistical Analysis Tool of Microsoft Excel 2003, Microsoft Office Professional Edition 2003 (Microsoft Co., Santa Rosa, CA, USA).

\section{Results and discussion}

\subsection{Isolating and identifying Alternaria sp.}

One hundred pomegranate fruit were collected from the local market of Taif City, KSA. All fruit were investigated for presence of fungal infection symptoms. Eighty-seven percentages of fruit appeared as healthy fruit with normal leathery exocarp. Twenty-three percentages of fruit appeared with black spot symptoms ranging from a single spot to more than $25 \%$ of the fruit surface (Fig. 2). Few spots consisted of a green-yellow halo surrounding a necrotic 
lesion. Damage to fruit was observed to the peel surface. Some fruit appeared with small reddish brown circular spots. Black spot symptoms have been noted on fruit, ranging from a single spot to more than $50 \%$ of the fruit surface (EzRA et al., 2010).
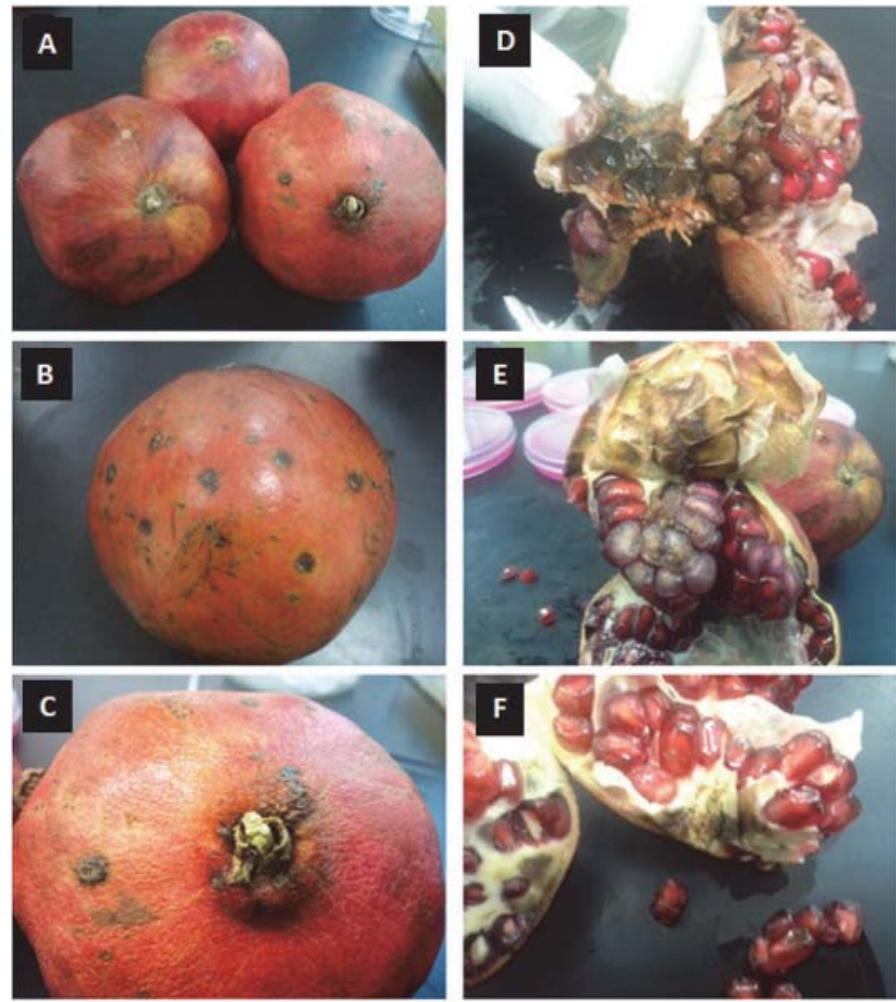

Fig. 2. Black spots infected pomegranate fruit (A, B, and C) and inside rotten tissues (D, E, and F). Black spots are singly distributed on the leathery exocarp or aggregated surrounding fruit-stalk. In some fruit, small black spots were distributed from calyx to fruit-stalk.

Both healthy-appearing and infected fruit were cut and investigated from the inside (Fig. 2). No fungal infection symptoms were noticed inside the healthy-appearing fruit. However, in the black-spotted fruit, the infection symptoms appeared on the edible parts (arils and seeds) in some fruit, whereas, in others both edible and non-edible parts were affected. Arils of infected fruit became pale, light brown, or dark brown. The fleshy mesocarp of some infected fruit appeared in light brown to dark brown. Moreover, the pulp membrane was also infected in some fruit and became dark brown to black (Fig. 2). Fungal colonies emerging from symptomatic tissue had morphology and conidia typical of Alternaria spp. Seven Alternaria isolates obtained from the edible parts were subjected to molecular identification by determining the partial sequence of the rDNA ITS region. All of sequenced strains were identified by similarity searches with ITS sequences in the NCBI database. The obtained results of the molecular identification ensured the presence of seven Alternaria strains belonging to two species; A. alternata (3 strains) and A. tenuissima (4 strains) with $100 \%$ identity percentage (Table 1 ). The obtained sequences of the seven strains were deposited to 
the EMBL/GenBank/DDBJ Nucleotide Sequence Data Libraries. The accession numbers and similarity percentage of the submitted sequences are illustrated in Table 1.

\subsection{In vitro mycotoxin production by Alternaria strains}

The seven identified Alternaria strains were tested for their ability to produce AOH, AME, and TA in rice at $25^{\circ} \mathrm{C}$ (Table 2). The strains were classified to low $(+)$, moderate $(++)$, and strong $(+++)$ producer of mycotoxins according to the classification categories described by Pose and co-workers (2010). All studied strains produce high quantities of AOH (strong$\mathrm{AOH}$ producers). A. tenuissima strains were strong-AME producers and moderate-TA producers, whereas A. alternata strains displayed moderate and low production of AME and TA, respectively. A. tenuissima strains showed high ability to form AME and TA compared with A. alternata strains. On the other hand, the level of TA toxin was produced in lower amounts compared with the quantities of $\mathrm{AOH}$ and AME produced by all tested strains. Generally, high percentage $(100 \%)$ of the isolated strains showed the ability to form all studied Alternaria toxins at different levels. These results were in accordance with those demonstrated in previous works by Alternaria species isolated from other fruit. RoBIGLIO and López (1995) isolated eleven A. alternata strains from mouldy core disease in "Red Delicious" apples. They stated that most of the isolates had the ability to produce AOH and AME toxins in the whole fruit. Recently, POSE and co-workers (2010) mentioned that $85.7 \%$ of Alternaria strains, isolated from "Moldy Heart" affected peaches, produced TA toxin, whereas $100 \%$ of the strains were able to form $\mathrm{AOH}$ and AME toxins in rice at $25^{\circ} \mathrm{C}$. In another work, only $64 \%$ of Alternaria strains isolated from tomato fruit produced TA (Pose et al., 2004).

Table 2. Mycotoxin production in rice at $25^{\circ} \mathrm{C}$ by Alternaria strains isolated from inner infected tissues of pomegranate fruit

\begin{tabular}{lccc}
\hline \multirow{2}{*}{ Strains } & \multicolumn{3}{c}{ Alternaria toxins } \\
\cline { 2 - 4 } & AOH & AME & TA \\
\hline A. tenuissima TUAa1 & +++ & +++ & ++ \\
A. tenuissima TUAa2 & +++ & +++ & ++ \\
A. tenuissima TUAa3 & +++ & +++ & + \\
A. alternata TUAa4 & +++ & ++ & + \\
A. alternata TUAa5 & +++ & ++ & ++ \\
A. alternata TUAa6 & +++ & +++ & + \\
A. tenuissima TUAa7 & +++ & & + \\
\hline
\end{tabular}

+: Low; ++: Moderate; +++: Stronger; This classification was suggested by Pose and co-workers (2010) as follows: AOH (alternariol): +: 0.04-0.15 $\mathrm{mg} \mathrm{g}^{-1},++: 0.16-0.27 \mathrm{mg} \mathrm{g}^{-1}$; +++: over $0.28 \mathrm{mg} \mathrm{g}^{-1}$.

AME (alternariol methyl ether): +: $0.07-0.24 \mathrm{mg} \mathrm{g}^{-1}$; ++: $0.25-0.41 \mathrm{mg} \mathrm{g}^{-1}$; +++: over $0.42 \mathrm{mg} \mathrm{g}^{-1}$.

TA (tenuazonic acid): +: 0.01-0.03 $\mathrm{mg} \mathrm{g}^{-1},++: 0.04-0.07 \mathrm{mg} \mathrm{g}^{-1}$; +++: over $0.08 \mathrm{mg} \mathrm{g}^{-1}$.

\subsection{Alternaria toxins in the pomegranate tissues}

The natural co-occurrence of Alternaria toxins was determined in the inner tissues of healthyappearing and black-spotted pomegranate fruit (Table 3). All healthy-appearing pomegranate fruit (87 samples) were negative to Alternaria toxins. On the other hand, all tested rotted tissues ( 23 samples) and most of healthy tissues of the black-spotted fruit (18 out of 23 
samples) proved positive to at least one Alternaria toxin investigated. This result indicates that Alternaria toxins can be distributed from the rotted tissues to the surrounding healthy tissues in black-spotted pomegranate fruit. The natural co-occurrence of all three tested toxins was recorded in 12 out of 23 rotted tissues and in only 2 out of 23 healthy tissues, whereas co-occurrence of two toxins was recovered from 7 and 5 rotted and healthy tissues, respectively.

Table 3. Natural co-occurrence of Alternaria toxins in healthy-appearing and black-spotted pomegranate fruit

\begin{tabular}{|c|c|c|c|c|c|c|}
\hline \multirow{2}{*}{ Pomegranate sample } & \multirow{2}{*}{$\begin{array}{l}\text { Total number of } \\
\text { tested samples }\end{array}$} & \multicolumn{4}{|c|}{ No. of samples containing Alternaria toxins } & \multirow{2}{*}{$\begin{array}{c}\text { No. of positive } \\
\text { samples }\end{array}$} \\
\hline & & 3 toxins & 2 toxins & 1 toxin & No toxin & \\
\hline Healthy-appearing fruit & 77 & 0 & 0 & 0 & 0 & 0 \\
\hline Black-spotted fruit & 23 & & & & & \\
\hline Rotten tissues & & 12 & 7 & 4 & 0 & 23 \\
\hline Healthy tissues ${ }^{\mathrm{a}}$ & & 2 & 5 & 11 & 5 & 18 \\
\hline
\end{tabular}

a: surrounding the rotten tissues

Table 4 shows the range and frequency percentage of the individual toxins in the pomegranate fruit. None of the investigated toxins was detected in the healthy-appearing pomegranate fruit. In the rotted tissues of black-spotted fruit, AME toxin was the highest determined toxin (2.14-32.02 $\mathrm{ng} \mathrm{g}^{-1} \mathrm{~d}$.w.) with frequency percentage of $95.6 \%$, followed by $\mathrm{AOH}$ and TA toxins. In the healthy tissues surrounding the rotted tissues, all toxins were also found but at lower levels compared with that measured in the rotted tissues (Table 4). This means that Alternaria toxins are not only found in the infected tissues, but also diffuse into the surrounding tissues at low levels. This finding is in agreement with those mentioned by Robiglio and López (1995). They have demonstrated that Alternaria toxins in apple fruit were not restricted to the rotted area, which was characterized by abundant fungal hyphae, but could be also recovered from the surrounding tissues. Another previous work had demonstrated that mycotoxins are released by the fungi into the surrounding substrate and contamination of agricultural products is therefore possible (BRZONKALIK et al., 2011).

\begin{tabular}{|c|c|c|c|c|c|c|}
\hline \multirow{3}{*}{ Sample (No.) } & \multicolumn{6}{|c|}{ Alternaria toxins } \\
\hline & \multicolumn{2}{|c|}{$\mathrm{AOH}$} & \multicolumn{2}{|c|}{ AME } & \multicolumn{2}{|c|}{ TA } \\
\hline & Range $^{\mathrm{a}}$ & Frequency $\%{ }^{\mathrm{b}}$ & Range $^{\mathrm{a}}$ & Frequency $\%{ }^{b}$ & Range $^{a}$ & Frequency $\%{ }^{\mathrm{b}}$ \\
\hline $\begin{array}{l}\text { Healthy-appearing } \\
\text { fruit ( } 87 \text { ) }\end{array}$ & ND & 0 & ND & 0 & ND & 0 \\
\hline $\begin{array}{l}\text { Black-spotted fruit } \\
\text { (23) }\end{array}$ & & & & & & \\
\hline Rotten tissues & $\begin{array}{c}1.86-19.20 \\
\pm 0.02\end{array}$ & 78 & $\begin{array}{l}2.14-32.02 \\
\quad \pm 0.02\end{array}$ & 95.6 & $\begin{array}{c}1.11-13.71 \\
\pm 0.01\end{array}$ & 69.5 \\
\hline Healthy tissues ${ }^{\mathrm{c}}$ & $\begin{array}{l}0.71-4.44 \\
\pm 0.01\end{array}$ & 43.5 & $\begin{array}{l}0.91-6.38 \\
\pm 0.01\end{array}$ & 61 & $\begin{array}{c}0.47-4.22 \\
\pm 0.01\end{array}$ & 17.4 \\
\hline
\end{tabular}

AOH: alternariol; AME: alternariol methyl ether; TA: tenuazonic acid; ND: not detectable under studied conditions a: calculated per gram dry weight of tissue (ng $\mathrm{g}^{-1}$ d.w.) \pm standard deviation

b: (No. of samples containing toxin/total no. of tested samples) $\times 100$

${ }^{c}$ : surrounding the rotted tissues 


\subsection{Alternaria toxins in pomegranate juices}

$\mathrm{AOH}, \mathrm{AME}$, and TA toxins were determined in two juice sets prepared from healthyappearing (H) and rotten (I) fruit. The effect of pasteurization and/or clarification on the level of Alternaria toxins was also studied (Table 5). None of the examined toxins was observed in the pomegranate juice set prepared from healthy-appearing fruit (RPJ-H, PROJ-H, CPJ-H, and PCPJ-H). In the pomegranate juice set prepared from the healthy tissues of the blackspotted fruit, all Alternaria toxins were detected at different concentrations. In raw pomegranate juice (RPJ-I) AOH, AME, and TA toxins were measured at level of 3.4, 4.6, and $1.65 \mathrm{ng} \mathrm{g}^{-1} \mathrm{~d}$.w., respectively. No significant differences were recorded in the tested Alternaria toxins after pasteurization (PRPJ-I) (Table 5). However, clarification process led to significant increase in the level of all tested toxins in the clarified pomegranate juice (CPJ-I). There is no significant effect of pasteurization on the level of Alternaria toxins in the clarified juice (PCPJ-I, Table 5).

Table 5. Alternaria toxins in pomegranate juices

\begin{tabular}{lccc}
\hline \multirow{2}{*}{ Juice $^{*}$} & \multicolumn{3}{c}{ Alternaria toxins ${ }^{\mathrm{a}}\left(\mathrm{ng} \mathrm{g}^{-1}\right.$ d.w. $)$} \\
\cline { 2 - 4 } & $\mathrm{AOH}$ & $\mathrm{AME}$ & $\mathrm{TA}$ \\
\hline RPJ-H & $\mathrm{ND}$ & $\mathrm{ND}$ & $\mathrm{ND}$ \\
PRPJ-H & $\mathrm{ND}$ & $\mathrm{ND}$ & $\mathrm{ND}$ \\
CPJ-H & $\mathrm{ND}$ & $\mathrm{ND}$ & $\mathrm{ND}$ \\
PCPJ-H & $\mathrm{ND}$ & $\mathrm{ND}$ & $1.65^{\mathrm{b}} \pm 0.02$ \\
RPJ-I & $3.40^{\mathrm{b}} \pm 0.01$ & $4.65^{\mathrm{b}} \pm 0.01$ & $2.65^{\mathrm{b}} \pm 0.02$ \\
PRPJ-I & $3.14^{\mathrm{b}} \pm 0.02$ & $4.49^{\mathrm{b}} \pm 0.02$ & $3.24^{\mathrm{a}} \pm 0.01$ \\
CPJ-I & $4.24^{\mathrm{a}} \pm 0.03$ & $5.84^{\mathrm{a}} \pm 0.02$ & $3.92^{\mathrm{a}} \pm 0.01$ \\
PCPJ-I & $4.85^{\mathrm{a}} \pm 0.02$ & $6.07^{\mathrm{a}} \pm 0.03$ & \\
\hline
\end{tabular}

AOH: alternariol; AME: alternariol methyl ether; TA: tenuazonic acid; ND: not detectable under studied conditions. Values in the same column with different letters differ significantly $(\mathrm{P}<0.05, \mathrm{n}=3)$

*: Juice types were described in Figure $1 ;{ }^{\text {a }}$ : calculated per gram dry weight of juice

To our best knowledge, there are no previous studies available on the natural occurrence of Alternaria toxins or the effect of pasteurization and clarification on these toxins in pomegranate juice. Many previous studies demonstrated that the toxic fungal secondary metabolites are thermally stable, therefore they might be transferred from contaminated rawfoods into the final products (Malachova et al., 2011). This statement could explain the insignificant effect of pasteurization on the level of Alternaria toxins in pomegranate juices.

The increasing amounts of Alternaria toxins after the clarification step could be explained by the presence of masked mycotoxins such as Alternaria toxin-glucoside, which is considered a mycotoxin derivative (MikULA et al., 2013). These masked mycotoxins may be degraded during the clarification step using the pectolytic enzymes solution, resulting in the release of the free $\mathrm{AOH}, \mathrm{AME}$, and TA toxins. 


\section{Conclusions}

AHO, AME, and TA toxins were present in the rotten and healthy parts of the black-spotted pomegranate fruit. In rotten tissues, AME toxin was the highest determined toxin with frequency percentage of $95.6 \%$, followed by $\mathrm{AOH}$ and TA. The removal of the rotten parts does not ensure the complete elimination of Alternaria toxins. Pasteurization and/or clarification were not sufficient to reduce Alternaria toxin concentrations in pomegranate juice. Therefore, close attention should be paid to the preparation of fruit juice to ensure its safety.

This work was supported by a grant (Contract No.1-434-2563) from Taif University, KSA.

\section{References}

BarkaI-Golan, R. (2008): Alternaria mycotoxins. -in: BARKaI-Golan, R. \& Nachman, P. (Eds) Mycotoxins in fruits and vegetables. Academic Press, San Diego, CA, USA, pp. 185-203.

Brzonkalik, K., Herrling, T., Syldatk, C. \& Neumann, A. (2011): Process development for the elucidation of mycotoxin formation in Alternaria alternata. AMB Express, 1, 27-35.

Buzrul, S., Alpas, H., Largeteau, A. \& Demazeau, G. (2008): Modeling high pressure inactivation of Escherichia coli and Listeria innocua in whole milk. Eur. Food Res. Technol., 227, 443-448.

Dahiwale, M.A., BaViskar, R.N. \& Suryawanshi, N.S. (2009): Integrated management of Alternaria alternata causing fruit rot of pomegranate. J. Life Sci., 6, 44-45.

Da Motta, S. \& Soares, V.L.M. (2000a): A method for the determination of two Alternaria toxins, alternariol and alternariol monomethyl ether, in tomato products. Braz. J. Microbiol., 31, 315-320.

Da Motta, S. \& Soares, V.L.M. (2000b): Simultaneous determination of tenuazonic and cyclopiazonic acids in tomato products. Food Chem., 71 111-116.

Elhariry, H., Bahobial, A.A. \& Gherbawy, Y. (2011): Genotypic identification of Penicillium expansum and the role of processing on patulin presence in juice. Food Chem. Toxicol., 49, 941-946.

Ezra, D., Gat, T., Skovorodnikova, Y., Vardi, Y. \& Kosto, I. (2010): First report of Alternaria black spot of pomegranate caused by Alternaria alternata in Israel. Australas. Plant Dis. Notes, 5, 1-2.

Farr, D.F., Rossman, A.Y., PAlm, M.E. \& McCray, E.B. (2007): Fungal databases, systematic botany \& mycology laboratory. ARS, USDA, http://nt.ars-grin.gov/fungaldatabases/, (last accessed: 21 September 2015)

GARDES, M. \& BRUND, T.D. (1993): ITS primers with enhanced specificity for basidiomycetes application to the identification of mycorrhizae and rusts. Mol. Ecol., 2, 113-118.

Malachova, A., Dzuman, Z., Veprikova, Z., Vaclavikova, M., Zachariasova, M. \& Hajslova, J. (2011): Deoxynivalenol, deoxynivalenol-3-glucoside, and enniatins: The major mycotoxins found in cereal-based products on the Czech market. J. Agr. Food Chem., 59, 12990-12997.

Mikula, H., Skrinjar, P., Sohr, B., Ellmer, D., Hametner, C. \& Fröhlich, J. (2013): Total synthesis of masked Alternaria mycotoxins - sulfates and glucosides of alternariol (AOH) and alternariol-9-methyl ether (AME). Tetrahedron, 69, 10322-10330.

Pantidou, M.E. (1973): Fungus-host index for Greece. Benaki Phytopathology Institute, Kiphissia, Athens, 382 pages.

Patras, A., Brunton, N.P., O’Donnell, C. \& Tiwari, B.K. (2010): Effect of thermal processing on anthocyanin stability in foods; mechanisms and kinetics of degradation. Trends Food Sci. Tech., 21, 3-11.

PitT, J.I. \& Hocking, A.D. (Eds) (1997): Fungi and food spoilage, $2^{\text {nd }}$ ed. Blackie Academic \& Professional, New South Wales, Australia, 592 pages.

Pose, G.N., Ludemann, V., Fernandez, D., Segura, J.A. \& Fernandez Pinto, V. (2010): Alternaria species associated with 'moldy heart' on peaches in Argentina. Trop. Plant Pathol., 35, 174-177.

Pose, G.N., Ludemann, V., Segura, J. \& Fernandez Pinto, V. (2004): Mycotoxin production by Alternaria strains isolated from tomatoes affected by Blackmold in Argentina. Mycotoxin Research, 20, 80-86. 
Rinaldi, M., Caligiani, A., Borgese, R., Palla, G., Barbanti, D. \& Massini, R. (2013): The effect of fruit processing and enzymatic treatments on pomegranate juice composition, antioxidant activity and polyphenols content. LWT-Food Sci. Technol., 53, 355-359.

Robiglio, A. \& LóPez, S. (1995): Mycotoxin production by Alternaria alternata strains isolated from red delicious apples in Argentina. Int. J. Food Microbiol., 24, 413-417.

Tziros, G.T., Lagopodi, A.L. \& Tzavella-Klonari, K. (2008): Alternaria alternata fruit rot of pomegranate (Punica granatum) in Greece. Plant Pathol., 57, 379.

Viuda-Martos, M., Fernández-López, J. \& Pérez-Állvarez, J.A. (2010): Pomegranate and its many functional components as related to human health: A review. Compr. Rev. Food Sci. F., 9, 635-654.

White, J.J., Bruns, T., Lee, S. \& TAylor, J. (1990): Amplification and direct sequencing of fungal ribosomal RNA genes for phylogenetics. -in: Innis, M.A., Gelfand, D.H., Sninsky, J.J. \& White, T.J. (Eds) PCR protocols: A guide to methods and applications. Academic Press, San Diego, pp. 315-322. 